\title{
Anti-platelet effects of anti-glaucomatous eye drops: an in vitro study on human platelets
}

\author{
This article was published in the following Dove Press journal: \\ Drug Design, Development and Therapy \\ 19 April 2017 \\ Number of times this article has been viewed
}

\author{
Marilita M Moschos' ${ }^{1,2}$ \\ Giannis A Moustafa! \\ Vasiliki D \\ Papakonstantinou ${ }^{3}$ \\ Michael Tsatsos ${ }^{4}$ \\ Konstantinos Laios' \\ Smaragdi Antonopoulou ${ }^{3}$ \\ 'Ist Department of Ophthalmology, \\ Medical School, University of \\ Athens, Athens, Greece; ${ }^{2}$ Biomedical \\ Research Foundation, Academy of \\ Athens, Athens, Greece; ${ }^{3}$ Laboratory \\ of Biology, Biochemistry, Physiology \\ and Microbiology, Department of \\ Nutrition and Dietetics, School \\ of Health Science and Education, \\ Harokopio University, Athens, Greece; \\ ${ }^{4}$ Royal Eye Infirmary, Dorset County \\ Hospital NHS Foundation Trust, \\ Dorchester, UK
}

Correspondence: Marilita M Moschos Ist Department of Ophthalmology, University of Athens, 6 lkarias Street, 14578, Ekali, Athens, Attica, Greece Tel +30 6944887319

Fax +30 21 0412 2139

Email moschosmarilita@yahoo.fr
Purpose: Altered platelet aggregability has been implicated in the pathogenesis of glaucoma. This study aims to investigate the anti-platelet potential of intraocular pressure lowering drops, with the possibility of establishing it as an additional mechanism of anti-glaucomatous action. Materials and methods: The anti-aggregating effects of a series of anti-glaucomatous eye drops were determined on human platelets in the platelet aggregation model, using four known aggregating factors (platelet activating factor [PAF], adenosine diphosphate [ADP], thrombin receptor-activating peptide [TRAP], and arachidonic acid [AA]).

Results: Almost all of the tested samples inhibited platelet aggregation induced by PAF, ADP, TRAP, and AA, except for Alphagan, which did not demonstrate inhibition of ADP- and TRAP-induced aggregation at a wide range of concentrations. Trusopt, Betoptic, and Azarga eye drops were the most potent inhibitors of all four aggregating factors, while Alphagan was the least potent $(P<0.05)$.

Conclusion: This study shows that anti-glaucomatous eye drops possess anti-platelet effects, and this was shown for the first time by experimenting on human platelets.

Keywords: glaucoma, eye, platelet, aggregation, PAF, TRAP

\section{Introduction}

Glaucoma is a progressive degenerative disease of the retina resulting in the death of the retinal ganglion cells, and constitutes a leading cause of irreversible blindness worldwide. The pathophysiology behind anatomic and functional damage inflicted by glaucoma is still not completely understood. Increased intraocular pressure (IOP) is the most established risk factor for this condition. ${ }^{1}$ However, occurrence of glaucomatous optic nerve damage is possible even in eyes with normal IOP, a condition characterized as normal- or low-tension glaucoma. This observation has led to the investigation of further possible risk factors, with endothelium-dependent vascular dysregulation being the most studied. ${ }^{2-7}$ Subsequent vascular insufficiency is believed to alter normal blood flow and generate damage to the optic nerve. It has also been hypothesized that episodes of transient ischemia and reperfusion add to the optic nerve injury. ${ }^{8}$

Another factor which is believed to contribute to the pathogenesis of glaucomatous optic nerve damage is increased platelet aggregability, possibly triggering microthrombosis of the retinal capillaries and the short ciliary arteries, which result in vascular damage and generate defects in the microcirculation of the optic nerve head. ${ }^{9-16}$ From very early on, Drance et al noticed an increased platelet adhesiveness (over $60 \%$ adhesiveness) in a subgroup of 45 patients with low-tension glaucoma. ${ }^{10}$ Hoyng et al observed a higher incidence of spontaneous platelet aggregation (SPA) in elderly patients with primary 
open angle glaucoma (POAG), independent of the presence or absence of vascular diseases, ${ }^{11}$ while in a follow-up study, the same group observed a high percentage of SPA in POAG patients with visual field deterioration. ${ }^{12}$ It also seems that these defects in platelet function are more pronounced in patients with low-tension glaucoma. ${ }^{16}$ Circulating platelet aggregate values are also high in glaucoma patients compared to healthy individuals, indicating a prothrombotic state. ${ }^{15}$

Considering the results of past studies showing that platelet hyperfunction may be associated with the pathogenesis of glaucoma, it is possible that anti-glaucomatous drugs may exert part of their action through interaction with the platelet aggregation process, in addition to their known pharmacological properties. This hypothesis motivated us to test the anti-platelet potential of a series of anti-glaucomatous eye drops, through inhibition of in vitro induced platelet aggregation. For the experiment, platelet-rich plasma (PRP) was isolated from healthy volunteers' blood, and aggregation was induced in vitro using four known aggregating factors (platelet activating factor [PAF], adenosine diphosphate [ADP], thrombin receptor-activating peptide [TRAP], and arachidonic acid [AA]). In our previous study, we examined the inhibitory effects of a series of anti-glaucomatous eye drops on PAF-induced aggregation in washed rabbit platelets. ${ }^{17}$ To our knowledge, the current study is the first to investigate this effect on human platelets, and the first to test ADP, TRAP, and AA, as well.

\section{Materials and methods}

\section{Materials and instrumentation}

Platelet aggregation assay was performed on a $490 \mathrm{X}$ model (Chrono-Log, Havertown, PA, USA). All aggregation factors (PAF, TRAP, AA, and ADP), as well as bovine serum albumin (BSA), were purchased from Sigma-Aldrich Co. (St Louis, MO, USA).

Acid-citrate-dextrose (ACD) anticoagulant solution was prepared by dissolving in water: citric acid (PanReac AppliChem, Inc., Maryland Heights, MO, USA), sodium citrate (Thermo Fisher Scientific, Waltham, MA, USA), and dextrose (Sigma-Aldrich Co.) to final concentrations of 0.065 M, 0.085 M, and $0.0111 \mathrm{M}$, respectively.

In this study, the following eye drops were tested: Alphagan (Allergan, Inc., Irvine, CA, USA), Azarga (Alcon Laboratories, Inc., Fort Worth, TX, USA), Betoptic (Alcon Laboratories, Inc.), Cosopt (MSD-Chibret, Mirabel, France), Duotrav (Alcon Laboratories, Inc.), Trusopt (MSD-Chibret), and Xalaprost (Aspen Pharma Pty Ltd, St Leonards, NSW, Australia).

\section{Methods}

Every volunteer signed an informed written consent to participate in the study, and the Ethics Committee of the G Gennimatas General Hospital of Athens approved the protocol. Human blood was collected from the antecubital vein of healthy volunteers, and transferred to four polyethylene tubes containing anticoagulant $(0.1 \mathrm{M}$ buffered dextrose citrate, ACD) in a ratio of blood/anticoagulant: $9 / 1(\mathrm{v} / \mathrm{v})$ to a final volume of $15 \mathrm{~mL}$. The isolation of PRP was obtained by centrifugation of blood specimens at $170 \times g$ for $18 \mathrm{~min}$. PRP was then transferred to polypropylene tubes at room temperature for the biological assay, whereas poor platelet plasma (PPP) was obtained by further centrifuging the specimens at $1,500 \times g$ for $25 \mathrm{~min}$. PRP was adjusted to 500,000 platelets $/ \mu \mathrm{L}$ using the respective PPP. All procedures took place at $24^{\circ} \mathrm{C}$ (room temperature).

The samples were dissolved in BSA and the induced aggregation was examined with PRP according to the method of Demopoulos et al. ${ }^{18}$ Each sample was added 1 min prior to the addition of the aggregation factor. The final concentration of each aggregating factor in the cuvette was $3.33 \mu \mathrm{M}$ for PAF, $0.82 \mu \mathrm{M}$ for ADP, $0.01 \mu \mathrm{M}$ for TRAP, and $0.15 \mu \mathrm{M}$ for AA. The induced platelet aggregation was measured before (considered as $0 \%$ inhibition), and after the addition of various concentrations of the examined sample. Consequently, the plot of percentage inhibition (ranging from $20 \%$ to $80 \%$ ) versus different concentrations of the sample was linear. From this curve, the concentration of the sample that inhibited 50\% factor-induced aggregation was calculated, and this value was defined as $\mathrm{IC}_{50}$. The minimum and maximum values of inhibition are demonstrated in Table 1. The experiments were performed in duplicate. $\mathrm{IC}_{50}$ results were reported in $\mu \mathrm{L}$ for each eye drop sample.

\section{Statistical analysis}

The results are expressed as mean and standard deviation. Differences between samples were tested with one-way ANOVA with post hoc analysis for multiple comparisons. Statistical significance was considered as $P<0.05$. The analysis was performed using SPSS Statistics 20 (IBM Corporation, Armonk, NY, USA).

\section{Results}

Our study results showed that almost all of the tested samples inhibited platelet aggregation induced by PAF, ADP, TRAP, and AA. An exception to this was observed in the case of Alphagan, which could not demonstrate inhibitory effects on ADP- and TRAP-induced aggregation at a wide 
Table I The minimum and maximum values of inhibition against TRAP, PAF, ADP, and AA, along with the corresponding volume of sample in the parenthesis

\begin{tabular}{|c|c|c|c|c|c|c|c|c|}
\hline \multirow[t]{2}{*}{ Samples } & \multicolumn{2}{|l|}{ TRAP } & \multicolumn{2}{|l|}{ PAF } & \multicolumn{2}{|l|}{ ADP } & \multicolumn{2}{|l|}{ AA } \\
\hline & $\begin{array}{l}\text { Min \% } \\
\text { ( } \mu \text { L sample) }\end{array}$ & $\begin{array}{l}\text { Max \% } \\
\text { ( } \mu \text { L sample) }\end{array}$ & $\begin{array}{l}\text { Min \% } \\
\text { ( } \mu \text { L sample) }\end{array}$ & $\begin{array}{l}\text { Max \% } \\
\text { ( } \mu \text { L sample) }\end{array}$ & $\begin{array}{l}\text { Min \% } \\
\text { ( } \mu \text { L sample) }\end{array}$ & $\begin{array}{l}\text { Max \% } \\
\text { ( } \mu \text { L sample) }\end{array}$ & $\begin{array}{l}\text { Min \% } \\
\text { ( } \mu \text { L sample) }\end{array}$ & $\begin{array}{l}\text { Max \% } \\
(\mu \mathrm{L} \text { sample) }\end{array}$ \\
\hline Trusopt & $7(17)$ & $84(48)$ & $31(I)$ & $89(30)$ & $13(0.2)$ & $94(5)$ & $7(20)$ & $96(30)$ \\
\hline Xalaprost & $7(6)$ & $99(48)$ & $19(10)$ & $93(45)$ & $8(\mathrm{I})$ & $92(44)$ & \multicolumn{2}{|c|}{$29(40)$} \\
\hline Betoptic & $13(10)$ & $93(47)$ & $19(2)$ & $96(45)$ & $18(0.1)$ & $94(20)$ & $29(20)$ & $93(30)$ \\
\hline Alphagan & \multicolumn{2}{|c|}{$7(47)$} & $13(15)$ & $91(45)$ & \multicolumn{2}{|c|}{ ND } & \multicolumn{2}{|c|}{ ND } \\
\hline Cosopt & \multicolumn{2}{|c|}{$40(47)$} & $29(2)$ & $75(10)$ & $30(I)$ & 7I (2) & \multicolumn{2}{|c|}{$43(40)$} \\
\hline Azarga & $13(0.5)$ & $73(47)$ & $44(I)$ & $83(5)$ & $7(2)$ & $84(10)$ & $27(10)$ & $53(30)$ \\
\hline Duotrav & \multicolumn{2}{|c|}{$65(47)$} & $7(2)$ & $73(45)$ & $7(2)$ & $73(44)$ & \multicolumn{2}{|c|}{$7(40)$} \\
\hline
\end{tabular}

Note: Inhibition was dose-dependent with some samples and stable (no demonstration of minimum and maximum values) with others.

Abbreviations: TRAP, thrombin receptor-activating peptide; PAF, platelet activating factor; ADP, adenosine diphosphate; AA, arachidonic acid; ND, not detected.

range of concentrations. Regarding Trusopt, $\mathrm{IC}_{50}$ in $\mu \mathrm{L}$ was $2.3 \pm 1.7,4.1 \pm 0.3,25.5 \pm 2.0,25.6 \pm 1.8$, Xalaprost, 15.9 \pm 2.1 , $15.8 \pm 1.7,16.5 \pm 1.6,70 \pm 1.5$, Betoptic, $2.1 \pm 0.2$, 4.7 \pm 1.1 , $25.4 \pm 0.9,20.9 \pm 1.9$, Cosopt, 3.2 $\pm 0.8,1.0 \pm 0.4,58.8 \pm$ 1.1, 46.7 \pm 1.3 , Azarga, $0.1 \pm 0.1,2.1 \pm 0.3,35.1 \pm 1.2,27.6 \pm 1.3$, Duotrav, 23.6 $\pm 0.9,23.8 \pm 1.2,176.3 \pm 21.8,23.8 \pm 1.3$, for PAF, ADP, TRAP, and AA, respectively. The $\mathrm{IC}_{50}$ in $\mu \mathrm{L}$ of Alphagan was $29 \pm 0.9$ and $352.5 \pm 21.2$ for PAF and TRAP, respectively. The aforementioned results are summarized in Table 2 and illustrated in Figure 1.

Concerning the statistical analysis, the results revealed that Trusopt, Betoptic, and Azarga were the most potent inhibitors in all four aggregation factors. On the other hand, Alphagan was the least potent. The rest of the eye drops, namely Xalaprost, Cosopt, and Duotrav showed an intermediate inhibitory action. In particular, regarding TRAP; Trusopt, Xalaprost, Betoptic, Cosopt, and Azarga displayed a similar inhibitory action, followed by Duotrav, and then Alphagan as the least potent inhibitor. For PAF; Azarga, Trusopt, Betoptic, and Cosopt were the most potent inhibitors, followed by Xalaprost, then Duotrav, and last Alphagan. Concerning ADP; Azarga, Cosopt, Trusopt, and Betoptic were the most potent inhibitors, followed by Xalaprost and then Duotrav, while Alphagan showed no inhibitory action at all. Regarding AA; Betoptic, Trusopt, Azarga, and Duotrav displayed the most potent inhibition, followed by Cosopt and then Xalaprost, while Alphagan showed no inhibitory action at all. In all cases $P<0.05$.

\section{Discussion}

A high IOP is generally accepted as a risk factor for glaucomatous optic nerve damage onset and progression. However, the increased IOP theory alone cannot explain the glaucomatous optic neuropathy observed in patients with normal IOP. Research has implicated vascular factors in the development of this type of injury. Past studies have demonstrated an association between glaucoma and a high degree of platelet aggregability. ${ }^{9-12,15,16}$ In the early 70 s, Begg et al recognized that small vessel disease was associated with glaucomatous atrophy of the optic nerve head, and characterized a hypercoagulable state as a predisposition for glaucoma. ${ }^{9}$ Two years later, Drance et al observed an increased platelet adhesiveness (over 60\%) in the majority of patients with low-tension glaucoma that they examined. ${ }^{10}$ A limitation of this study was that no group was

Table $2 I_{50}$ values for each sample after stimulation with each of the four aggregating factors, compared using one-way ANOVA

\begin{tabular}{|c|c|c|c|c|c|c|c|c|}
\hline \multirow[t]{2}{*}{ Samples } & \multicolumn{8}{|c|}{$I_{50}(\mu L) \pm S D$} \\
\hline & TRAP & & PAF & & ADP & & AA & \\
\hline a) Trusopt & $25.5^{\mathrm{d}, \mathrm{g}}$ & \pm 2.0 & $2.3^{b, d, g}$ & \pm 1.7 & 4. $I^{b, g}$ & \pm 0.3 & $25.6^{\mathrm{b}, \mathrm{e}}$ & \pm 1.8 \\
\hline b) Xalaprost & $16.5^{\mathrm{d}, \mathrm{g}}$ & \pm 1.6 & I5.9 $9^{\mathrm{a}, \mathrm{c}, \mathrm{d}, \mathrm{e}, \mathrm{f}, \mathrm{g}}$ & \pm 2.1 & $15.8^{\mathrm{a}, \mathrm{c}, \mathrm{e}, \mathrm{f}, \mathrm{g}}$ & \pm 1.7 & $70.0^{\mathrm{a}, \mathrm{c}, \mathrm{e}, \mathrm{f}, \mathrm{g}}$ & \pm 1.5 \\
\hline c) Betoptic & $25.4^{\mathrm{d}, \mathrm{g}}$ & \pm 0.9 & $2 . I^{\mathrm{b}, \mathrm{d}, \mathrm{g}}$ & \pm 0.2 & $4.7^{\mathrm{b}, \mathrm{g}}$ & $\pm I . I$ & $20.9^{\mathrm{b}, \mathrm{e}}$ & \pm 1.9 \\
\hline d) Alphagan & $352.5^{\mathrm{a}, \mathrm{b}, \mathrm{c}, \mathrm{e}, \mathrm{f,g}}$ & \pm 21.2 & $29.0^{a, b, c, c, f, g}$ & \pm 0.9 & - & - & - & - \\
\hline e) Cosopt & $58.8^{\mathrm{d}, \mathrm{g}}$ & \pm 1.1 & $3.2^{\mathrm{b}, \mathrm{d}, \mathrm{g}}$ & \pm 0.8 & $1.0^{\mathrm{b}, \mathrm{g}}$ & \pm 0.4 & $46.7^{\mathrm{a}, \mathrm{b}, \mathrm{c}, \mathrm{f}, \mathrm{g}}$ & \pm 1.3 \\
\hline f) Azarga & $35 . I^{d, g}$ & \pm 1.2 & $0 . I^{b, d, g}$ & \pm 0.1 & $2 . I^{b, g}$ & \pm 0.3 & $27.6^{\mathrm{b}, \mathrm{e}}$ & \pm 1.3 \\
\hline g) Duotrav & $176.3^{\mathrm{a}, \mathrm{b}, \mathrm{c}, \mathrm{d}, \mathrm{e}, \mathrm{f}}$ & \pm 21.8 & $23.6^{\mathrm{a}, \mathrm{b}, \mathrm{b}, \mathrm{d}, \mathrm{d}, \mathrm{e}, \mathrm{f}}$ & \pm 0.9 & $23.8^{\mathrm{a}, \mathrm{b}, \mathrm{c}, \mathrm{e}, \mathrm{f}}$ & \pm 1.2 & $23.8^{\mathrm{b}, \mathrm{e}}$ & \pm 1.3 \\
\hline
\end{tabular}

Notes: $I C_{50}$ was defined as the concentration of the sample needed to inhibit $50 \%$ of factor-induced aggregation. The results are expressed as mean values $( \pm$ SD) of two separate experiments. The exponent after each value expresses the statistically significant difference with the sample that the exponent represents from the first column, $P<0.05$.

Abbreviations: TRAP, thrombin receptor-activating peptide; PAF, platelet activating factor; ADP, adenosine diphosphate; AA, arachidonic acid; SD, standard deviation. 


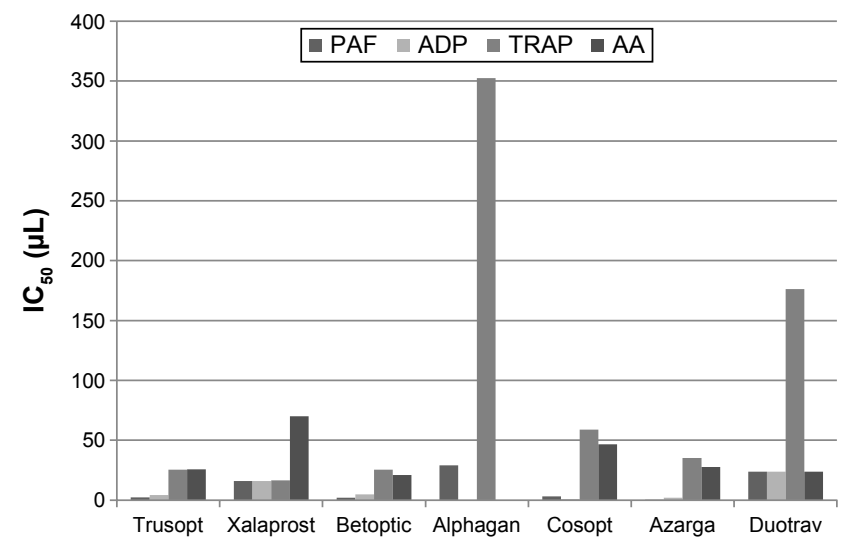

Figure I Graphical depiction of the $I_{50}$ values for each sample after stimulation with each of the four aggregating factors.

Abbreviations: PAF, platelet activating factor; ADP, adenosine diphosphate; TRAP, thrombin receptor-activating peptide; $A A$, arachidonic acid.

used for statistical comparison regarding this outcome. The studies of Hoyng et al shed new light on the topic. Their team tested platelet aggregation in 79 patients with POAG, and in 81 patients with ocular hypertension but no glaucomatous damage, to find a higher incidence of SPA in patients with POAG over 70 years of age. ${ }^{11}$ Remarkably, the high incidence of SPA in patients with POAG was observed to be independent of the presence or absence of vascular diseases. ${ }^{11}$ In a follow-up study, the same group observed a higher percentage of SPA in POAG patients with visual field deterioration, compared to POAG patients without visual field loss and patients with ocular hypertension but no visual field defects. ${ }^{12}$ A Croatian study reported a higher ratio of circulating platelet aggregates in patients with advanced glaucoma accompanied by visual loss, compared to healthy controls. ${ }^{15}$ However, the same team failed to demonstrate a statistically significant difference in circulating platelet aggregates between patients with POAG and progression of visual field loss, and patients with POAG and non-progressive loss of visual fields, even though circulating platelet aggregate values were pathologic and higher in the former group. ${ }^{19}$ Nevertheless, this observation does not exclude increased platelet aggregability as a risk factor for glaucomatous optic nerve injury. It is increasingly accepted that the pathogenesis of glaucoma is multifactorial, and indeed high platelet aggregability cannot solely explain visual field loss in glaucoma patients. A Japanese study confirmed the role of platelet hyper-aggregation in glaucoma. They observed that an increased platelet aggregation as defined by ADP- or collagen-induced abnormal secondary aggregation in-vitro is frequently associated with glaucoma patients. ${ }^{16}$ Interestingly, this tendency is more apparent in patients with normal-tension glaucoma. ${ }^{16}$
The exact mechanism of glaucomatous damage due to platelet hyper-aggregation is not clear. It has been postulated that microcirculatory defects, such as vasoconstriction and retention of blood, damage endothelial cells, leading to sub-endothelial collagen exposure which triggers platelet aggregation, subsequently causing ischemic injury of the optic nerve. ${ }^{12,16,20}$ The Ocular Hypertension Treatment Study demonstrated that occurrence of disc hemorrhage predisposes to the development of $\mathrm{POAG},{ }^{21}$ while later Shim et $\mathrm{al}^{22}$ claimed that micro-infarctions within the optic nerve head and retinal circulatory disorders may be the cause of disc hemorrhages in patients with normal-tension glaucoma. ${ }^{9,22-24}$ Platelets indeed seem to play a role in this process. However, the primary risk factor for disc hemorrhages in these experiments was found to be delayed-instead of increased - platelet aggregation. ${ }^{22}$ A possible cause of platelet hyper-reactivity in patients with glaucoma may involve the pigment epithelium-derived factor (PEDF). PEDF is a multifunctional secreted protein that has been found to possess antithrombogenic, anti-angiogenic, and vasculoprotective properties in vivo, thereby protecting against vascular events. ${ }^{25-28}$ Also, PEDF suppresses occlusive thrombus formation by inhibiting platelet activation and aggregation in rats through its anti-oxidative properties. ${ }^{29}$ In glaucomatous eyes, PEDF is significantly reduced, ${ }^{30} \mathrm{a}$ fact which may predispose to increased platelet aggregability and the establishment of a thrombogenic state. A final explanation could be that platelet aggregates exclusively promote an elevated IOP by blocking the physiological pores of Schlemm's canal. ${ }^{31}$ Platelets' role is fundamental in the function of the inner wall of Schlemm's canal. ${ }^{31}$ A disruption or alteration in their function may result in extensive pore occlusion and decreased aqueous humor drainage. However, this does not explain low-tension glaucoma.

This study examined, for the first time in scientific literature, the anti-platelet properties of anti-glaucomatous drugs as determined by inhibition of in vitro induced human platelet aggregation using four known aggregating factors (PAF, ADP, TRAP, and AA). Our previous study determined the anti-aggregating effects of anti-glaucomatous drugs on washed rabbit platelets, and after stimulation by PAF only. ${ }^{17}$ Our results indicate that anti-glaucomatous drugs exhibit anti-platelet properties. In general, the most potent inhibition was seen when aggregation was induced by PAF and ADP, and it was less apparent with TRAP and AA. Concerning the drugs, Azarga, Betoptic, and Trusopt demonstrated the most potent inhibitory action, while Alphagan was the least potent. It is quite interesting that each tested eye drop 
displayed a nearly similar effect on the four different aggregation factors. This fact indicates that general/non-specific, instead of specific, inhibition exists that may be crucial at a clinical practice level.

Unfortunately, there are no large studies examining the role of platelet hyper-aggregation in glaucoma, and most of our reviewed studies have included a limited number of patients and controls. Another limitation of our study, is that we are not able to conclude whether the anti-aggregating effect of the tested eye drops is due to the active ingredients, or due to included excipients in the drugs. Finally, in our experiments, we did not examine the role of the coagulation cascade and the fibrinolytic system, which are concomitantly activated with the platelet aggregation process, and have also been mentioned in studies investigating the vascular mechanisms behind glaucomatous optic nerve damage. ${ }^{10,16,32-34}$ We hope that this information will be a topic of interest in future studies launched by our results.

It is important that we investigate the pathophysiology behind glaucomatous optic damage with a broad and holistic approach. Currently, increased IOP is the best-established risk factor. ${ }^{1}$ Yet, it does not explain glaucomatous optic damage observed in patients with normal IOP. Altered platelet aggregability is a potential risk factor for this disorder. Preliminary results of our project show that IOP lowering eye drops can have an effect on platelets and inhibit their aggregation process. This anti-platelet potential may be another mechanism through which these drugs halt glaucoma progression. Known anti-platelet agents, and their effect on glaucoma optic neuropathy progression should be the topic of research in future targeted studies. For instance, a long-term anti-platelet therapy (eg, low-dose aspirin) trial in patients with glaucoma - a suggestion made by other research teams as well ${ }^{16,35}$ - is a good idea to study this topic at the level of the intervention.

\section{Disclosure}

The authors report no conflicts of interest in this work.

\section{References}

1. Agarwal R, Gupta SK, Agarwal P, Saxena R, Agrawal SS. Current concepts in the pathophysiology of glaucoma. Indian J Ophthalmol. 2009; 57(4):257-266.

2. Sugiyama T, Moriya S, Oku H, Azuma I. Association of endothelin-1 with normal tension glaucoma: clinical and fundamental studies. Surv Ophthalmol. 1995;39 Suppl 1:S49-S56.

3. Gass A, Flammer J, Linder L, Romerio SC, Gasser P, Haefeli WE. Inverse correlation between endothelin-1-induced peripheral microvascular vasoconstriction and blood pressure in glaucoma patients. Graefes Arch Clin Exp Ophthalmol. 1997;235(10):634-638.

4. Noske W, Hensen J, Wiederholt M. Endothelin-like immunoreactivity in aqueous humor of patients with primary open-angle glaucoma and cataract. Graefes Arch Clin Exp Ophthalmol. 1997;235(9):551-552.
5. Tezel G, Kass MA, Kolker AE, Becker B, Wax MB. Plasma and aqueous humor endothelin levels in primary open-angle glaucoma. J Glaucoma. 1997;6(2):83-89.

6. Orgul S, Prunte C, Flammer J. Endothelium-derived vasoactive substances relevant to normal-tension glaucoma. Curr Opin Ophthalmol. 1998; 9(2):88-94.

7. Cioffi GA, Sullivan P. The effect of chronic ischemia on the primate optic nerve. Eur J Ophthalmol. 1999;9 Suppl 1:S34-S36.

8. Drance SM. Some factors in the production of low tension glaucoma. Br J Ophthalmol. 1972;56(3):229-242.

9. Begg IS, Drance SM, Sweeney VP. Ischaemic optic neuropathy in chronic simple glaucoma. Br J Ophthalmol. 1971;55(2):73-90.

10. Drance SM, Sweeney VP, Morgan RW, Feldman F. Studies of factors involved in the production of low tension glaucoma. Arch Ophthalmol. 1973;89(6):457-465.

11. Hoyng PF, Greve EL, Frederikse K, Geijssen C, Oosting H. Platelet aggregation and glaucoma. Doc Ophthalmol. 1985;61(2):167-173.

12. Hoyng PF, de Jong N, Oosting H, Stilma J. Platelet aggregation, disc haemorrhage and progressive loss of visual fields in glaucoma. A seven year follow-up study on glaucoma. Int Ophthalmol. 1992; 16(2):65-73.

13. Schroer H, Scheurer G, Behrens-Baumann W. Vascular occlusion of the retina - an experimental model. II. Platelet aggregates. Graefes Arch Clin Exp Ophthalmol. 1992;230(3):281-285.

14. Boerrigter RM, Siertsema JV, Kema IP. Serotonin (5-HT) and the rat's eye. Some pilot studies. Doc Ophthalmol. 1992;82(1-2):141-150.

15. Bojic L, Skare-Librenjak L. Circulating platelet aggregates in glaucoma. Int Ophthalmol. 1998;22(3):151-154.

16. Matsumoto M, Matsuhashi H, Nakazawa M. Normal tension glaucoma and primary open angle glaucoma associated with increased platelet aggregation. Tohoku J Exp Med. 2001;193(4):293-299.

17. Moschos MM, Chatziralli IP, Stamatakis G, Papakonstantinou VD, Tsatsos M, Demopoulos CA. In vitro effects of anti-glaucomatous eye drops on platelet-activating factor and its metabolism. Semin Ophthalmol. 2017;32(2):198-203.

18. Demopoulos CA, Pinckard RN, Hanahan DJ. Platelet-activating factor. Evidence for 1-O-alkyl-2-acetyl-sn-glyceryl-3-phosphorylcholine as the active component (a new class of lipid chemical mediators). J Biol Chem. 1979;254(19):9355-9358.

19. Bojic L, Mandic Z, Bukovic D, Karelovic D, Strinic T. Circulating platelet aggregates and progression of visual field loss in glaucoma. Coll Antropol. 2002;26(2):589-593.

20. Yau JW, Teoh H, Verma S. Endothelial cell control of thrombosis. BMC Cardiovasc Disord. 2015;15:130.

21. Budenz DL, Anderson DR, Feuer WJ, et al. Detection and prognostic significance of optic disc hemorrhages during the Ocular Hypertension Treatment Study. Ophthalmology. 2006;113(12):2137-2143.

22. Shim SH, Kim JM, Woo HY, Shin KU, Koh JW, Park KH. Association between platelet function and disc hemorrhage in patients with normal-tension glaucoma: a prospective cross-sectional study. Am J Ophthalmol. 2015;160(6):1191-1199.

23. Sonnsjo B, Dokmo Y, Krakau T. Disc haemorrhages, precursors of open angle glaucoma. Prog Retin Eye Res. 2002;21(1):35-56.

24. Krakau CE, Bengtsson B, Holmin C. The glaucoma theory updated. Acta Ophthalmol (Copenh). 1983;61(5):737-741.

25. Yamagishi S, Matsui T. Pigment epithelium-derived factor (PEDF) and cardiometabolic disorders. Curr Pharm Des. 2014;20(14):2377-2386.

26. Yamagishi SI, Matsui T. Anti-atherothrombogenic properties of PEDF. Curr Mol Med. 2010;10(3):284-291.

27. Yamagishi S, Matsui T, Nakamura K, Takenaka K. Pigment epitheliumderived factor (PEDF) inhibits collagen-induced platelet activation by reducing intraplatelet nitrotyrosine levels. Int J Cardiol. 2010;140(1): 121-122.

28. Yamagishi S, Matsui T, Nakamura K, Takenaka K. Administration of pigment epithelium-derived factor prolongs bleeding time by suppressing plasminogen activator inhibitor-1 activity and platelet aggregation in rats. Clin Exp Med. 2009;9(1):73-76. 
29. Takenaka K, Yamagishi S, Matsui T, et al. Pigment epithelium-derived factor (PEDF) administration inhibits occlusive thrombus formation in rats: a possible participation of reduced intraplatelet PEDF in thrombosis of acute coronary syndromes. Atherosclerosis. 2008;197(1):25-33.

30. Ogata N, Matsuoka M, Imaizumi M, Arichi M, Matsumura M. Decreased levels of pigment epithelium-derived factor in eyes with neuroretinal dystrophic diseases. Am J Ophthalmol. 2004;137(6):1129-1130.

31. Hamanaka T, Bill A. Platelet aggregation on the endothelium of Schlemm's canal. Exp Eye Res. 1994;59(3):249-256.

32. Mehra KS, Dube B, Mikuni I, Dube RK. Reduced fibrinolytic activity in aqueous humor of chronic simple glaucoma. Tokai J Exp Clin Med. 1984; 9(1):33-34.
33. Mehra KS, Dube B, Dube RK. Reduced fibrinolytic activity in aqueous humour in glaucoma. Indian J Ophthalmol. 1983;31(5):592-593.

34. Mehra KS, Dube B, Dube RK. Fibrinolytic activity in blood and aqueous humour in glaucoma. Indian J Ophthalmol. 1983;31 Suppl:827-829.

35. Pache M, Flammer J. A sick eye in a sick body? Systemic findings in patients with primary open-angle glaucoma. Surv Ophthalmol. 2006; 51(3):179-212.

\section{Publish your work in this journal}

Drug Design, Development and Therapy is an international, peerreviewed open-access journal that spans the spectrum of drug design and development through to clinical applications. Clinical outcomes, patient safety, and programs for the development and effective, safe, and sustained use of medicines are the features of the journal, which has also been accepted for indexing on PubMed Central. The manuscript management system is completely online and includes a very quick and fair peer-review system, which is all easy to use. Visit http://www.dovepress.com/testimonials.php to read real quotes from published authors.

Submit your manuscript here: http://www.dovepress.com/drug-design-development-and-therapy-journal 